Developing environmentally acceptable agricultural chemicals and pest control products, as well as breeding soya bean and hybrid cotton seed. Working on plant growth improvement.

\section{Zurn Industries Inc}

20300 Woodinville-Snohomish Road,

Woodinville WA 98072-9604

Tel: 2064814272

offer engineering, design and construction

services for wood fired electricity

generating systems in the megawatt range as well as large steam generating systems $(50,000$ to $500,000 \mathrm{lbs} / \mathrm{hr})$, through subsidiaries the National Energy Production Corporation (NEPCO), Bumstead-Woolford Co and the Atlantic-Gulf Co (US).

Zymogenetics Inc

2121 North 35th Street, Seattle WA 98103

Tel: 2066354036 Tlx: 294890

Undertake contract research in relation to genetic engineering of yeasts and other fungi.

\title{
WEST INDIES
}

Jamaica Scientific Research Council Hope Gardens, PO Box 350, Kingston 6 , Jamaica Tel: 92744714

Have constructed and installed medium sized Chinese model biogas plants and several family sized plants using soil-cement aggregate or concrete. Have introduced plastic biogas plants of 15 cubic metre and
50 cubic metre size as part of the Jamaican Government Biogas Technology Programme.

Tropicana International (Jamaica) Ltd 7 Surbiton Road, Kingston 10, Jamaica Tel: 8099291371

Commercial installation producing anhydrous ethanol for fuel use.

\section{YUGOSLAVIA}

\section{Bratsvo}

Ilindenska 46,24106 Subotica

Tel: 02423762 Tlx: 15138 yu vagoni

Contractors for construction of biogas

production facilities.

\section{CECOS}

Centre for Comparative studies on

Technological and Social Progress, Svetozara Markovica 6, 21000 Novi Sad

Tel: 021623658

Carry out assessments of new technology and its effect on society.

\section{Maize Research Institute}

Institut za Kukuruz, Zemun Polje, PO Box 89, 11081 Zemun

Tel: 011217434

Major maize breeding centre, also carrying out research on aspects of productivity and photosynthesis in relation to biomass yield.
University in Novi Sad

Faculty of Agriculture, Institute of Field and Vegetable Crops, Department for Sorghum and Energy Crops, 21470 Backi Petrovac

Tel: 02178365 TIx: 14204 tezbpc yu Carrying out breeding programmes to increase biomass production for energy crops including sweet sorghum and artichokes.

\section{Vojvodinainvest}

Institute for Research Development and Investment, Bul M Tita 3/II, 21000 Novi Sad Tel: 02124277 Tlx: 14481 yu vins Large agricultural investment bank with interests in maize and soybean projects. Have carried out investigations into the availability and suitability of agricultural residues for energy generation. 